\title{
MULTIVARIATE ANALYSIS OF MORPHOLOGICAL TRAITS AND THE MOST IMPORTANT PRODUCTIVE TRAITS OF WHEAT IN EXTREME WET CONDITIONS
}

\author{
LuKović, K. ${ }^{1 *}$ - Prodanović, S. ${ }^{2}$ - Perišić, V. ${ }^{1}$ - Milovanović, M. ${ }^{3}-$ PerišIĆ, V. ${ }^{4}-$ \\ RAJIČIĆ, V. ${ }^{4}-$ ZEČEVIĆ, $V^{5}$ \\ ${ }^{1}$ Centre for Small Grains, Save Kovačevića 31, 34000 Kragujevac, Serbia \\ ${ }^{2}$ Faculty of Agriculture, University of Belgrade, Nemanjina 6, 1100 Belgrade, Serbia \\ ${ }^{3}$ Technical Vocational College, Nemanjina 2, 12000 Požarevac, Serbia \\ ${ }^{4}$ Faculty of Agriculture, University of Niš, Kosančićeva 4, 37000 Kruševac, Serbia \\ ${ }^{5}$ Megatrend University, Belgrade, Faculty of Biofarming, Maršala Tita 39, 24300 Bačka \\ Topola, Serbia \\ ${ }^{*}$ Corresponding author \\ e-mail: kika@kg.ac.rs
}

(Received $6^{\text {th }}$ Mar 2020; accepted $9^{\text {th }}$ Jul 2020)

\begin{abstract}
In these studies, 14 winter wheat (Triticum aestivum ssp vulgare L.) genotypes were analyzed in three localities across the Republic of Serbia. Some morphological and the most important productive traits were analysed in order to determine the relationship between grain yield and these traits in the year with extreme wet conditions during period of intensive wheat development (April-June period). According to our results, period of stem extension, heading and grain filling characterized by lower air temperatures and extremely high rainfall at all three localities, had detrimental effects on the grain filling process. The genotypes KG-191/5-13 and KG-1/6 achieved above average values of the most desirable traits in all three localities, and can be singled out as desirable parents in breeding programs to create new and improved varieties of wheat. Based on the principal component analysis and cluster analysis, two groups of similar genotypes were distinguished. The highest degree of positive correlation was found between diameter of the first internode and diameter of top internode; number of spikelets per spike and number of fertile spikelets per spike; grain mass/spike and grain mass/plant; plant height and length of the top internode.
\end{abstract}

Keywords: wheat, precipitation, yield, Principal Component Analysis, clustergram

Abbreviations: PH, plant height; LFI, length of the first internode; LTI, length of the top internode; DFI, diameter of the first internode; DTI, diameter of the top internode; LFL, length of the flag leaf; WFL, width of the flag leaf; SL, spike length; NSS, number of spikelets per spike; NFS, number of fertile spikelets; GMS, grain mass per spike; GMP, grain mass per plant; Y, grain yield; PCA, Principal Component Analysis; ANOVA, analysis of variance

\section{Introduction}

In most wheat breeding programs, the main focus is on grain yield and yield components (number of spikes per unit area, spike length, number of spikelets per spike, number of grains per spike, grain mass per spike and mass of 1000 grains). Araus et al. (2008) points out that such an approach has enabled the advancement of production in line with the growing population of the planet, while the contribution of breeding in Serbia in the second half of the 20th century is measured by increasing the genetic potential for grain yield of 32-43 kg ha years $^{-1}$ (Mladenov et al., 2007). Today's 
predictions about future breeding of wheat and other cereals are largely based on existing and future climate change, with drought being one of the key stress factors for production.

However, analysis of trends and intensity of precipitation, both on an annual and seasonal or monthly basis in the territory of Serbia, indicate an increase in annual precipitation sums in the northern and central parts of Serbia from the middle and the end of 1990's, as in the first decades of the 21st century, relative to the multi-year average (Stanojević, 2012; Tošić and Unkašević, 2013). Extreme wet conditions in some years were a crucial factor concerning grain yield, as well as technological quality in the period of intensive wheat development (period April-June). Xu et al. (2018) found that in this particular period of wheat development, the SPEI values of the Drought Indicator (Standardized Precipitation Evapotranspiration Index) and soil moisture status exhibit a stronger relationship with yield than other stages of growth and development. Excessive precipitation and soil water lead to losses in wheat yield (Zampieri et al., 2017), due to a stronger attack of pests and diseases, nutrient leaching from the soil, difficulty in oxygen uptakeby roots, and difficulty performing work operations (eg. harvesting). As an example, the authors cites 2016 and the yield losses recorded in France stemming from such an extreme year.

Selection of short stature wheat varieties with greater ability to utilize nutrients from fertilizers are a major feature of genetic improvement in wheat (Bhutta et al., 2006) and the basis of increased genetic potential for yield. Even so, lodging is one of the crucial factors in yield formation (Yao et al., 2011), even in short, and dwarf wheat varieties in the case of insufficient stalk strength. The existence of broad genetic variability for stem diameter, wall thickness, and stem material strength as components of stem strength has been identified, but the lack of utilization of this source of variability is due to the breeder's lack of knowledge of the importance of these traits and the difficulty in evaluating them (Berry et al., 2007; Berry and Berry, 2015). Yu et al. (2003) emphasize the necessity of combining the mechanical strength of the stem and other desirable features in order to increase the resistance to lodging.

The paper examines wheat genotypes selected at the Center for Small Grains Kragujevac (Serbia) to determine the relationship between the final grain yield and individual morphological traits as components of the mechanical strength of the stem, as well as the most important productive traits in the year with extreme wet conditions.

\section{Material and Methods}

\section{Plant material}

In these studies, 14 winter wheat genotypes were analyzed (Triticum aestivum ssp vulgare L.), of which 13 genotypes represent promising selection lines created at the Center for Small Grains in Kragujevac (KG - 47/21, KG - 52/3, KG - 1/6, KG - 60-3 / 3, $\mathrm{KG}-52 / 23, \mathrm{KG}-40-39 / 3, \mathrm{KG}-191 / 5-13, \mathrm{KG}-162 / 7, \mathrm{KG}-28 / 6, \mathrm{KG}-307 / 4, \mathrm{KG}-$ 199/4, KG - 244/4, KG-27/6), and one standard variety (Pobeda). The studied wheat lines and their pedigree are shown in Table 1.

\section{Field trials and methods}

The exploratory part of the experiment was carried out during 2013/14 in three localities: Institute of forage plants in Kruševac $\left(21^{\circ} 21^{\prime} \mathrm{E}, 43^{\circ} 34^{\prime} \mathrm{N}, 166 \mathrm{~m}\right)$, 
Agroinstitute in Sombor (19 $\left.09^{\circ} \mathrm{E}, 45^{\circ} 46^{\prime} \mathrm{N}, 87 \mathrm{~m}\right)$ and the Center for Small Grain in Kragujevac $\left(20^{\circ} 56^{\prime} \mathrm{E}, 44^{\circ} 02^{\prime} \mathrm{N}, 185 \mathrm{~m}\right)$. The experiment was performed under field conditions according to a completely random block system, in three repetitions with the size of the basic plot of $5 \mathrm{~m}^{2}(5 \times 1 \mathrm{~m})$. Within the plot, 10 rows were planted, with a row spacing of $10 \mathrm{~cm}$. The sowing was done mechanically using 600-650 germinated grains per $\mathrm{m}^{2}$ depending on the characteristics of the genotype.

Table 1. Examined genotypes of winter bread wheat and their pedigree

\begin{tabular}{|c|c|}
\hline Genotypes & Pedigree \\
\hline 1. $\mathrm{KG}-27 / 6$ & ○ L-100/97 x §̂ Pobeda \\
\hline 2. $\mathrm{KG}-244 / 4$ & 우 (L-1165 x SSK-20/96) x $ð$ Vizija \\
\hline 3. $K G-199 / 4$ & ㅇ L-35/93 x $ð$ Pobeda \\
\hline 4. $\mathrm{KG}-307 / 4$ & $q$ Pobeda $x \lesssim$ Duga \\
\hline 5. $\mathrm{KG}-28 / 6$ & + L-100/97 x $\widehat{o}$ Pobeda \\
\hline 6. $\mathrm{KG}-162 / 7$ & o L-246/6 x ô Studenica \\
\hline 7. $\mathrm{KG}-191 / 5-13$ & 우 [(Pi $159102 \times$ Evropa $) \times$ Studenica $]$ x ठ KG-2086 \\
\hline 8. $\mathrm{KG}-40-39 / 3$ & q Vizija x $\lesssim$ KG 100 \\
\hline 9. $\mathrm{KG}-52 / 23$ & + Bujna $\mathrm{x} \partial \mathrm{KG}-56-\mathrm{S}$ \\
\hline 10. $\mathrm{KG}-60-3 / 3$ & q $\mathrm{KG} 100 \mathrm{x}$ ○े SSK 50 01/02 \\
\hline 11. $\mathrm{KG}-1 / 6$ & q KG 100 x §̂ Toplica \\
\hline 12. $\mathrm{KG}-52 / 3$ & q Vizija x $\overbrace{}^{\Uparrow}($ Bujna x KG $-56-S)$ \\
\hline 13. $\mathrm{KG}-47 / 21$ & + Vizija x $\widehat{o}$ (Lazarica x Takovčanka) \\
\hline 14. Pobeda & o Sremica $\mathrm{x} \widehat{\jmath}$ Balkan \\
\hline
\end{tabular}

The most important stages of the wheat development, from heading to full maturity, and 10-day periods of precipitation during May and June are presented in the Table 2.

Table 2. Dates of developmental phases of wheat and precipitation during May and June 2014

\begin{tabular}{|c|c|c|c|c|c|c|}
\hline \multirow{2}{*}{ Locality } & \multicolumn{6}{|c|}{ Developmental phases } \\
\hline & \multicolumn{2}{|c|}{ Heading } & Flowering & Milk stage & \multicolumn{2}{|c|}{ Full maturity } \\
\hline Kragujevac & \multicolumn{2}{|c|}{29 April - 8 May } & 4-12 May & 30 May - 5 Jun & \multicolumn{2}{|c|}{26 Jun - 5 July } \\
\hline Sombor & \multicolumn{2}{|c|}{28 April - 5 May } & 3 - 9 May & 30 May - 2 Jun & \multicolumn{2}{|c|}{25 Jun - 1 July } \\
\hline Kruševac & \multicolumn{2}{|c|}{ 3-8 May } & 9-11 May & 31 May -3 Jun & \multicolumn{2}{|c|}{27 Jun - 5 July } \\
\hline \multicolumn{7}{|c|}{ Precipitation $(\mathrm{mm})$} \\
\hline \multirow{2}{*}{ Locality } & \multicolumn{3}{|c|}{ May } & \multicolumn{3}{|c|}{ June } \\
\hline & $\mathrm{I}$ & II & III & $\mathrm{I}$ & II & III \\
\hline Kragujevac & 66.6 & 100.7 & 60 & 6.5 & 23.5 & 36.9 \\
\hline Sombor & 62.3 & 53 & 29.7 & 5.4 & 14.9 & 46.9 \\
\hline Kruševac & 45.3 & 61 & 20.3 & 16.6 & 30.7 & 68 \\
\hline
\end{tabular}

During the study, at each site, 45 plants total (three replications every with 15 plants $3 \times 15)$ were selected from each genotype tested, at the stage of full maturity, to obtain data on the following morphological and productive traits: plant height (PH), length of the first internode (LFI), length of the top internode (LTI), diameter of the first internode (DFI), diameter of the top internode (DTI), spike length (SL), number of spikelets per spike (NSS), number of fertile spikelets (NFS), grain mass per spike (GMS), grain mass per 
plant (GMP). Length of the flag leaf (LFL), and width of the flag leaf (WFL) were measured during the stage of milk maturity. After the harvest, grain yield (Y) was measured for each plot in three replications and then converted to $t \mathrm{ha}^{-1}$.

\section{Properties of soil}

The field experiment in Kragujevac was carried out on a plot of smonitza-type soil. Chemical analysis of the soil showed acidic reaction, lower humus content, provided with a moderate amountsof the total nitrogen and readily accessible phosphorus. The content of readily available potassium was high. Soil at the Kruševac locality was alluvium in degradation. Humus, total nitrogen and readily available phosphorus were moderately provided, while the amount of readily available potassium in the tiller layer was high. The basic type of soil on which the experiment was conducted in Sombor is a chernozem. It is expressed alkaline reaction, and optimum amount of humus. Total nitrogen is moderately provided while easily accessible phosphorus was provided optimally. The readily available potassium content is high (Table 3 ).

Table 3. Agrochemical analysis of soil

\begin{tabular}{c|c|c|c|c|c}
\hline Locality & pH in KCL & Humus (\%) & $\mathbf{N}(\%)$ & $\mathbf{P}_{\mathbf{2}} \mathbf{O}_{\mathbf{5}}(\mathbf{m g})$ & $\mathbf{K}_{\mathbf{2}} \mathbf{O}(\mathbf{m g})$ \\
\hline Kragujevac & 4.91 & 2.51 & 0.16 & 17.6 & 29.2 \\
Kruševac & 5.45 & 2.97 & 0.146 & 11.3 & 31.08 \\
Sombor & 7.59 & 3.54 & 0.17 & 19.6 & 28.9 \\
\hline
\end{tabular}

\section{Climatic conditions during the trial period}

The average values of monthly air temperatures and precipitation amounts by months during the trial period as well as multi-year averages are shown in Figs. 1, 2 and 3. All three localities are characterized by slightly higher air temperatures during October and November. The months of December in Sombor, February in Kruševac, as well as December and February in Kragujevac, are characterized by a dry period with extremely low precipitation, which led to slower plant development (Figs 1, 2 and 3).

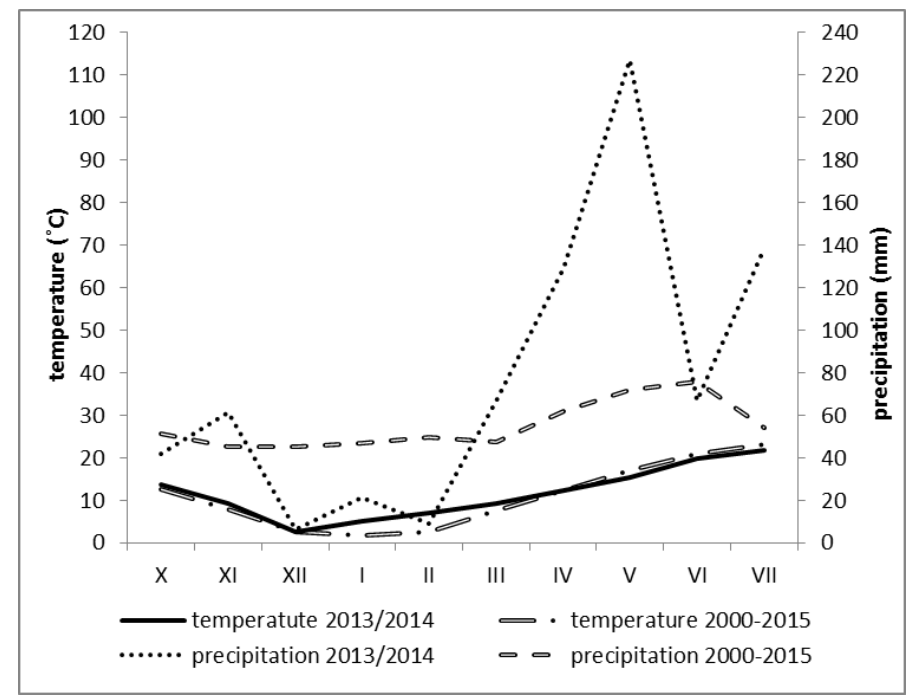

Figure 1. Average monthly air temperatures and total amount of precipitation in Kragujevac during 2013/14 and multi-year average (2000-2015) 


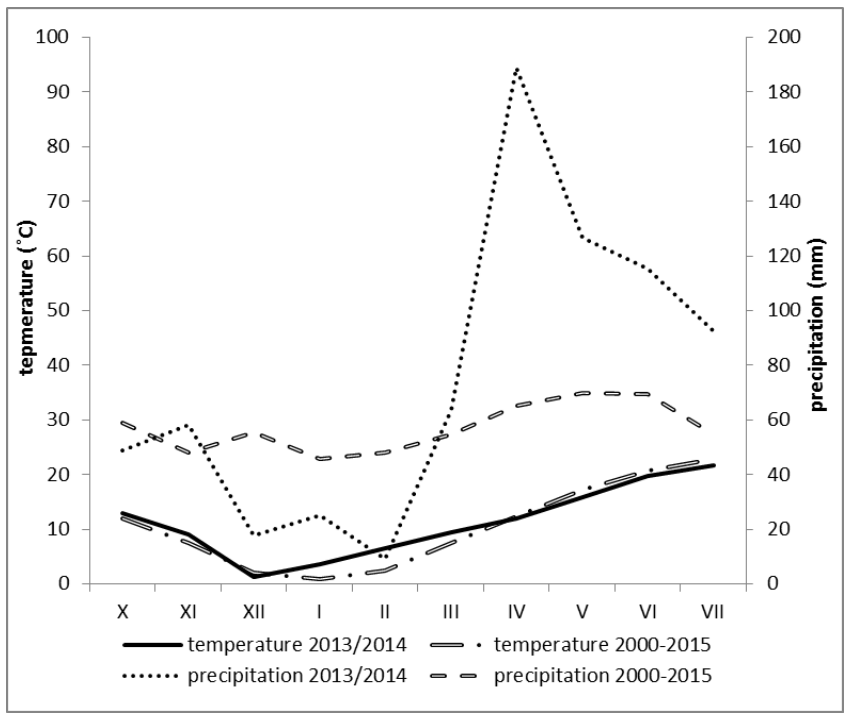

Figure 2. Average monthly air temperatures and total amount of precipitation in Kruševac during 2013/14 and multi-year average (2000-2015)

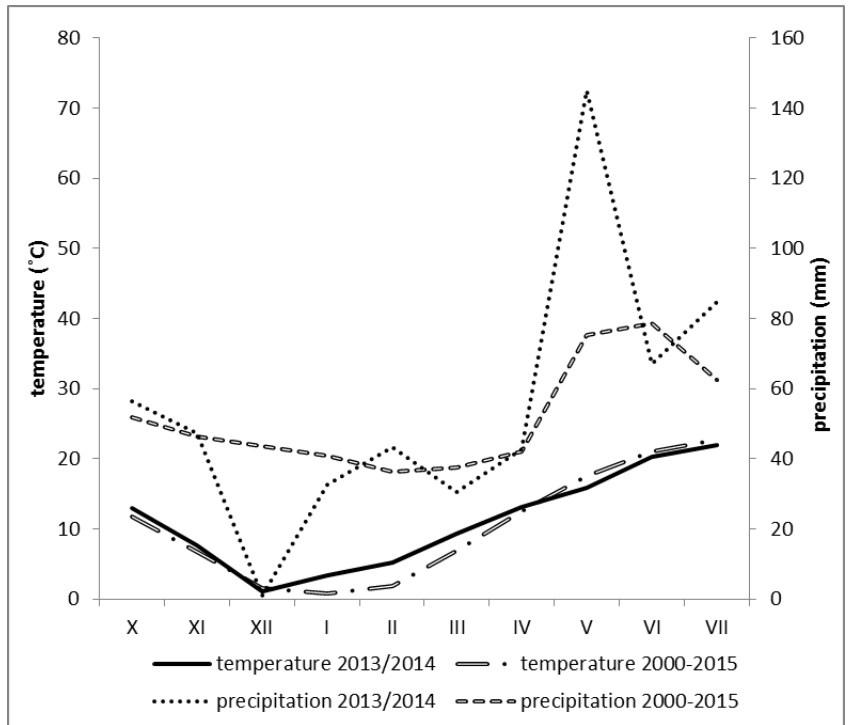

Figure 3. Average monthly air temperatures and total amount of precipitation in Sombor during 2013/14 and multi-year average (2000-2015)

Typically, the year of the trial is extremely high in precipitation by month. Thus, in April, $129.1 \mathrm{~mm}$ of precipitation occurred in Kragujevac and $188.8 \mathrm{~mm}$ in Kruševac, which is three times higher than the multi-year average. There were about $48.9 \mathrm{~mm}$ of rainfall in Sombor during the same period. The flowering period and the beginning of grain filling (during May) are characterized by lower air temperatures in all three localities, as well as extremely high rainfall, twice as high in Sombor and Kruševac (145 $\mathrm{mm}$ and $126.6 \mathrm{~mm}$ compared to the multi-year average of $75.4 \mathrm{~mm}$ and $66 \mathrm{~mm}$, respectively), and even three times higher than the average of many years in Kragujevac (227 mm compared to $71.8 \mathrm{~mm}$ ). 
In April and May alone, there were $356 \mathrm{~mm}$ of precipitation in the Kragujevac area, which is about $50 \%$ of the total rainfall during the wheat growing season. Such large amounts of precipitation led to the excessive amounts of the surface water in the trial field in Kruševac and Kragujevac, which later reflected on the yield and quality of the wheat grain.

\section{Statistical data processing}

For all analyzed morphological and productive properties of wheat, the following parameters of descriptive statistics were calculated: mean, standard deviation as a measure of absolute variation and coefficient of variation as a measure of relative variation. Heritability in the broad sense was calculated as the ratio of genotypic to phenotypic variance.

To examine the effect of genotype and locality on the morphological and productive traits of wheat, a two-factor ANOVA model using a completely random block system was used through the SPSS-22 statistical program. Duncan's test was used for subsequent comparisons. A 5\% significance level was used in all tests. To mark significant differences between genotypes, a lowercase Latin letters were used.

Principal Component Analysis (PCA) was used to examine the contribution of individual morphological and productive traits to overall variability in order to summarize data and interpret results more clearly. The number of components extracted for further analysis was determined by the Guttman-Keiser criterion. Further analysis retained components with an Eigen value greater than 1. This analysis was performed in XLSTAT software.

A clustergram was used to group genotypes by their similarity in the traits tested, as well as to group these traits by their correlation. All data are standardized (reduced to zero average and unit deviation). The Euclidean distance calculated on standardized data was used as a measure of similarity of some genotypes, and Pearson's correlation coefficient subtracted from 1 . The average method was used for grouping. MATLAB R2018a was used for clustering.

\section{Results}

\section{Analysis of morphological traits}

The lowest average stem height at all three studied sites belonged to the KG-1/6 genotype $(78.5 \mathrm{~cm})$ while the highest was KG-162/7 genotype $(102.3 \mathrm{~cm})$. Compared to the standard Pobeda variety, the nine lines had lower stem height on average (Table 4).

The length of the first internode ranged from $3.5 \mathrm{~cm}$ (KG-1/6) to $5.1 \mathrm{~cm}(\mathrm{KG}-191 / 5-$ 13) on average. The highest average length of the top internode at all sites had the KG244/4 genotype $(37.7 \mathrm{~cm}$ ) and the lowest were genotypes KG-27/6 and KG-28/6 $(25.4 \mathrm{~cm})$.

Different mean values of stem diameter (internode) were determined between analyzed genotypes. On average, the largest internode diameter was achieved by Pobeda $(4.0 \mathrm{~mm})$, and the smallest genotype KG-191/5-13 $(3.5 \mathrm{~mm})$, which had the smallest diameter of the top internode $(3.1 \mathrm{~mm})$ as well. The KG-1/6 genotype achieved, on average, the largest diameter of the top internode $(4.1 \mathrm{~mm})$. 
Table 4. Descriptive statistics and heritability for morphological traits of studied wheat genotypes

\begin{tabular}{|c|c|c|c|c|c|c|c|}
\hline Genotype & PH & LFI & LTI & DFI & DTI & LFL & WFL \\
\hline KG-27/6 & $80.9^{\mathrm{ab} *}$ & $4^{b}$ & $25.4^{\mathrm{a}}$ & $3.8^{\mathrm{bcd}}$ & $3.7^{\mathrm{cd}}$ & $20.52^{\mathrm{ab}}$ & $1.77^{\mathrm{abcd}}$ \\
\hline KG-244/4 & $97.7^{\mathrm{f}}$ & $4.1^{\mathrm{bcd}}$ & $37.7^{\mathrm{g}}$ & $3.8^{\mathrm{bcd}}$ & $3.9^{\mathrm{efg}}$ & $20.6^{\mathrm{ab}}$ & $1.64^{\mathrm{a}}$ \\
\hline KG-199/4 & $85.6^{\mathrm{cd}}$ & $4^{\mathrm{bc}}$ & $28.3^{\text {cd }}$ & $3.8^{\mathrm{bcd}}$ & $4 f^{g}$ & $19.9^{\mathrm{a}}$ & $1.86^{\text {bcde }}$ \\
\hline KG-307/4 & $92.6^{\mathrm{e}}$ & $4^{\mathrm{b}}$ & $29.6^{\mathrm{ef}}$ & $3.8^{\mathrm{bcd}}$ & $3.9^{\mathrm{ef}}$ & $24.29^{\mathrm{f}}$ & $1.66^{\mathrm{a}}$ \\
\hline KG-28/6 & $80.8^{\mathrm{ab}}$ & $4.1^{\mathrm{bcd}}$ & $25.4^{\mathrm{a}}$ & $3.8^{\mathrm{bcd}}$ & $3.7^{\mathrm{c}}$ & $20.2^{\mathrm{ab}}$ & $1.87^{\mathrm{de}}$ \\
\hline KG-162/7 & $102.3^{\mathrm{g}}$ & $4.5^{\mathrm{f}}$ & $30.7^{\mathrm{f}}$ & $3.9^{\text {cd }}$ & $3.8^{\mathrm{cd}}$ & $21.5^{\mathrm{abcd}}$ & $1.69^{\mathrm{a}}$ \\
\hline KG-191/5-13 & $98.6^{\mathrm{f}}$ & $5.1^{\mathrm{f}}$ & $28.5^{\mathrm{de}}$ & $3.5^{\mathrm{a}}$ & $3.1^{\mathrm{a}}$ & $20.6^{\mathrm{ab}}$ & $1.86^{\mathrm{bcde}}$ \\
\hline KG-40-39/3 & $83^{\mathrm{bc}}$ & $4.2^{\text {bcde }}$ & $28.3^{\mathrm{cd}}$ & $3.9^{\text {cd }}$ & $4^{\mathrm{fg}}$ & $23.3^{\text {ef }}$ & $1.87^{\text {cde }}$ \\
\hline KG-52/23 & $94^{\mathrm{e}}$ & $4.5^{\mathrm{ef}}$ & $29.9^{f}$ & $3.6^{\mathrm{ab}}$ & $3.5^{\mathrm{b}}$ & $22.3^{\text {cde }}$ & $1.71^{\mathrm{ab}}$ \\
\hline KG-60-3/3 & $86.9^{\mathrm{d}}$ & $4.4^{\mathrm{def}}$ & $28.3^{\text {cd }}$ & $3.8^{\mathrm{bcd}}$ & $3.8^{\mathrm{de}}$ & $21^{\mathrm{abc}}$ & $1.71^{\mathrm{ab}}$ \\
\hline KG-1/6 & $78.5^{\mathrm{a}}$ & $3.5^{\mathrm{a}}$ & $26.8^{\mathrm{b}}$ & $3.9^{\text {cd }}$ & $4.1^{\mathrm{g}}$ & $21.8^{\text {bcde }}$ & $1.92^{\mathrm{e}}$ \\
\hline KG-52/3 & $84.1^{\mathrm{c}}$ & $4.3^{\text {cdef }}$ & $26.4^{\mathrm{ab}}$ & $3.8^{\mathrm{bc}}$ & $3.7^{\mathrm{cd}}$ & $21.7^{\text {bcde }}$ & $1.69^{\mathrm{a}}$ \\
\hline KG-47/21 & $87.7^{\mathrm{d}}$ & $4.3^{\text {cdef }}$ & $27.2^{\mathrm{bc}}$ & $3.7^{\mathrm{bc}}$ & $3.8^{\mathrm{de}}$ & $22.8^{\mathrm{def}}$ & $1.7^{\mathrm{a}}$ \\
\hline Pobeda & $93.3^{\mathrm{e}}$ & $3.9^{\mathrm{b}}$ & $28.3^{\text {cd }}$ & $4^{\mathrm{d}}$ & $3.9^{\mathrm{ef}}$ & $20.6^{\mathrm{ab}}$ & $1.72^{\mathrm{abc}}$ \\
\hline Average & 89 & 4.2 & 28.6 & 3.8 & 3.8 & 21.5 & 1.76 \\
\hline CV (\%) & 8.6 & 10.9 & 11 & 5.4 & 7 & 14.65 & 13.7 \\
\hline $\mathbf{s}$ & 7.7 & 0.5 & 3.2 & 0.2 & 0.3 & 3.5 & 0.3 \\
\hline $\mathrm{h}^{2}(\%)$ & 98.22 & 93.98 & 96.53 & 62.32 & 95.57 & 86.26 & 73.07 \\
\hline
\end{tabular}

Legend: PH- plant height $(\mathrm{cm})$; LFI- length of the first internode $(\mathrm{cm})$; LTI- length of the top internode $(\mathrm{cm})$; DFI-diameter of the first internode (mm); DTI-diameter of the top internode (mm); LFL- length of the flag leaf $(\mathrm{cm})$; WFL- width of the flag leaf $(\mathrm{cm})$; CV $(\%)$ - coefficient of variation; s- standard deviation; $\mathrm{h}^{2}(\%)$-heritability in the broad sense. *Distinct letters in the row indicate significant differences according to Duncan test $(\mathrm{P} \leq 0.05)$.

The highest average values of flag-leaf length were determined for the KG-47/21 genotype $(22.8 \mathrm{~cm})$, while the largest flag-leaf width was achieved by the KG-1/6 genotype $(1.92 \mathrm{~cm})$.

\section{Productive trait analysis}

The average values for the length of the primary spike indicate that 10 genotypes were better in respect to the Pobeda variety, with the highest length being KG-191/5-13 $(11.6 \mathrm{~cm})$ and the smallest KG-60-3/3 $(7.7 \mathrm{~cm})$.

The KG-27/6 genotype averaged about 23 spikelets in the primary spike, which is the highest value for all three localities, while the smallest spikelets number was distinguished by KG-60-3/3 (19.6). Grain mass per spike varied from $1.3 \mathrm{~g}$ (KG-27/6, KG-28/6, KG-52/3) up to $1.9 \mathrm{~g}$ (KG-52/23), while genotype KG-60-3/3 achieved the highest average grain mass per plant as well as the highest average yield at all localities $\left(5.6 \mathrm{~g} ; 5.6 \mathrm{t} \mathrm{ha}^{-1}\right)($ Table 5$)$.

\section{Principal Components Analysis and Clustergram}

Principal Component Analysis (PCA) reduced the 13 observed variables to the five principal components, which absorbed most of the variation in the observed properties. The five components account for $90.215 \%$ of the total data variation. The first major component comprises the largest part of the total variance, while each subsequent 
component represents the largest remaining part. Thus, the first component explains $34.772 \%$ of the data variation, the second $22.525 \%$, the third $13.966 \%$, the fourth $10.423 \%$ and the fifth component $8.528 \%$ (Table 6).

Table 5. Descriptive statistics and heritability for production traits of studied wheat genotypes

\begin{tabular}{|c|c|c|c|c|c|c|}
\hline Genotype & SL & NSS & NFS & GMS & GMP & $\mathbf{Y}$ \\
\hline KG-27/6 & $10.4^{\mathrm{efg}}$ & $22.6^{\mathrm{g}}$ & $20.2^{\mathrm{f}}$ & $1.3^{\mathrm{ab}}$ & $3.6^{\mathrm{a}}$ & $4.5^{\text {abcde }}$ \\
\hline KG-244/4 & $8.9^{\mathrm{b}}$ & $20.2^{\mathrm{ab}}$ & $19^{\mathrm{bc}}$ & $1.6^{\text {bcde }}$ & $4.9^{\mathrm{cd}}$ & $3.9^{\mathrm{a}}$ \\
\hline KG-199/4 & $9.3^{\mathrm{c}}$ & $20.3^{\mathrm{b}}$ & $17.9^{\mathrm{a}}$ & $1.5^{\mathrm{abcd}}$ & $4.3^{\mathrm{abc}}$ & $4.8^{\text {bcde }}$ \\
\hline KG-307/4 & $9.8^{\mathrm{d}}$ & $20.5^{\mathrm{bc}}$ & $18.5^{\mathrm{ab}}$ & $1.6^{\text {cdef }}$ & $4.7^{\mathrm{bcd}}$ & $4.9^{\text {cdef }}$ \\
\hline KG-28/6 & $10.4^{\mathrm{ef}}$ & $22.2^{\mathrm{fg}}$ & $20^{\mathrm{ef}}$ & $1.3^{\mathrm{a}}$ & $3.8^{\mathrm{ab}}$ & $4.4^{\mathrm{abcde}}$ \\
\hline KG-162/7 & $9.7^{\mathrm{d}}$ & $21.7^{\mathrm{ef}}$ & $20^{\mathrm{ef}}$ & $1.5^{\text {abcde }}$ & $4.6^{\mathrm{bcd}}$ & $4.3^{\mathrm{abcd}}$ \\
\hline KG-191/5-13 & $11.6^{\mathrm{i}}$ & $20.7^{\mathrm{bcd}}$ & $19.3^{\text {cde }}$ & $1.6^{\text {cdef }}$ & $4.4^{\mathrm{abc}}$ & $4.9^{\text {cdef }}$ \\
\hline KG-40-39/3 & $10.7^{\mathrm{h}}$ & $21.7^{\mathrm{ef}}$ & $19.7^{\mathrm{cdef}}$ & $1.5^{\mathrm{abcd}}$ & $4.3^{\mathrm{abc}}$ & $4.2^{\mathrm{abc}}$ \\
\hline KG-52/23 & $10.1^{\mathrm{e}}$ & $20.5^{b c}$ & $18.5^{\mathrm{ab}}$ & $1.9^{\mathrm{f}}$ & $5.5^{\mathrm{d}}$ & $5.1^{\mathrm{ef}}$ \\
\hline KG-60-3/3 & $7.7^{\mathrm{a}}$ & $19.6^{\mathrm{a}}$ & $17.8^{\mathrm{a}}$ & $1.6^{\text {bcde }}$ & $5.6^{\mathrm{d}}$ & $5.6^{\mathrm{f}}$ \\
\hline KG-1/6 & $10.6^{\mathrm{fgh}}$ & $21.7^{\mathrm{ef}}$ & $20.3^{\mathrm{f}}$ & $1.7^{\mathrm{def}}$ & $4.7^{\mathrm{bcd}}$ & $4.7^{\text {bcde }}$ \\
\hline KG-52/3 & $10.5^{\mathrm{fgh}}$ & $21.2^{\text {cde }}$ & $19^{\mathrm{bc}}$ & $1.3^{\mathrm{ab}}$ & $4.2^{\mathrm{abc}}$ & $4.4^{\mathrm{abcd}}$ \\
\hline KG-47/21 & $10.7^{\mathrm{gh}}$ & $21.7^{\text {ef }}$ & $19.2^{\mathrm{bcd}}$ & $1.4^{\mathrm{abc}}$ & $4.3^{\mathrm{abc}}$ & $4.1^{\mathrm{ab}}$ \\
\hline Pobeda & $9.5^{\mathrm{cd}}$ & $21.4^{\mathrm{de}}$ & $19.8^{\mathrm{def}}$ & $1.8^{\mathrm{ef}}$ & $5.2^{\mathrm{cd}}$ & $5 d^{\text {ef }}$ \\
\hline Average & 10 & 21.1 & 19.2 & 1.6 & 4.6 & 4.6 \\
\hline $\mathrm{CV}$ & 7.9 & 5.1 & 5.4 & 18.3 & 22.2 & 16.5 \\
\hline $\mathbf{s}$ & 1 & 1.1 & 1 & 0.3 & 1 & 0.8 \\
\hline $\mathbf{h}^{2}(\%)$ & 98.24 & 93.38 & 87.78 & 86.67 & 73.28 & 48.08 \\
\hline
\end{tabular}

Legend: SL- spike length (cm); NSS- number of spikelets per spike; NFS-number of fertile spikelets; GMS-grain mass per spike (g); GMP- grain mass per plant (g); Y-yield $\left(\mathrm{t} \mathrm{ha}^{-1}\right)$. CV (\%)-coefficient of variation; s-standard deviation; $\mathrm{h}^{2}(\%)$-heritability in the broad sense. ${ }^{*}$ Distinct letters in the row indicate significant differences according to Duncan test $(\mathrm{P} \leq 0.05)$.

Table 6. Eigenvalues and \% of explained variability by five main components

\begin{tabular}{c|c|c|c}
\hline Factor & Eigenvalue ( $\boldsymbol{\lambda})$ & \% of variance & Cumulative (\%) \\
\hline $\mathbf{1}$ & 4.520 & 34.772 & 34.772 \\
$\mathbf{2}$ & 2.928 & 22.525 & 57.298 \\
$\mathbf{3}$ & 1.816 & 13.966 & 71.263 \\
$\mathbf{4}$ & 1.355 & 10.423 & 81.686 \\
$\mathbf{5}$ & 1.109 & 8.528 & 90.215 \\
\hline
\end{tabular}

The value for loadings (loadings $>0.60$ ) was used as the criterion for determining the affiliation of individual variables to the principal components. The first component was defined by six parameters (NSS, NFS, PH, LTI, GMS and GMP). The second component is in strong positive correlation with DFI and DTI, and negative correlation with LFI and SL. The third component is defined by the yield that it is positively correlated and the LTI with which it is negatively correlated. The fourth component was defined by grain mass per spike and the fifth component, which accounted for the smallest $\%$ of variability, was defined by the length of the flag leaf (Table 7). 
Table 7. Loadings of five main components

\begin{tabular}{c|c|c|c|c|c}
\hline Variable & $\mathbf{1}$ & $\mathbf{2}$ & $\mathbf{3}$ & $\mathbf{4}$ & $\mathbf{5}$ \\
\hline PH & -0.6736 & -0.2821 & -0.5384 & 0.1307 & -0.2705 \\
LFI & -0.3802 & -0.8273 & -0.1208 & -0.1070 & 0.0292 \\
LTI & -0.6202 & 0.1758 & -0.6184 & -0.1041 & -0.1959 \\
DFI & 0.3209 & 0.8577 & -0.1152 & 0.0851 & -0.2109 \\
DTI & 0.2042 & 0.9382 & -0.0822 & -0.0471 & 0.1423 \\
SL & 0.5743 & -0.6174 & -0.1386 & 0.4322 & 0.1302 \\
NSS & 0.8986 & -0.0686 & -0.1939 & 0.2018 & -0.1510 \\
NFS & 0.7377 & -0.0499 & -0.2915 & 0.3757 & -0.4106 \\
Y & -0.5247 & -0.0123 & 0.7661 & 0.1855 & -0.0717 \\
GMS & -0.6227 & 0.1590 & 0.1068 & 0.7017 & -0.2286 \\
GMP & -0.8546 & 0.2559 & 0.1301 & 0.3126 & -0.1103 \\
LFL & -0.0581 & 0.1394 & -0.2566 & 0.5336 & 0.7766 \\
WFL & 0.5561 & -0.1616 & 0.5308 & 0.1634 & -0.2145 \\
\hline
\end{tabular}

Marked loadings are $>0.60$, legend:PH- plant height $(\mathrm{cm})$; LFI- length of the first internode $(\mathrm{cm})$; LTIlength of the top internode $(\mathrm{cm})$; DFI-diameter of the first internode $(\mathrm{mm})$; DTI-diameter of the top internode $(\mathrm{mm})$; LFL- length of the flag leaf $(\mathrm{cm})$; WFL- width of the flag leaf $(\mathrm{cm})$; SL- spike length $(\mathrm{cm})$; NSS- number of spikelets per spike; NFS-number of fertile spikelets; GMS-grain mass per spike (g); GMP- grain mass per plant (g); Y-yield ( $\left.\mathrm{tha}^{-1}\right)$

\section{Biplot analysis}

Biplot analysis was used to more clearly understand the relationship between genotypes and morphologically productive traits. Fig. 4 shows the biplot PCA analysis of morphological and productive traits, whose abscission of the coordinate system is the first and the ordinate is a second major component.

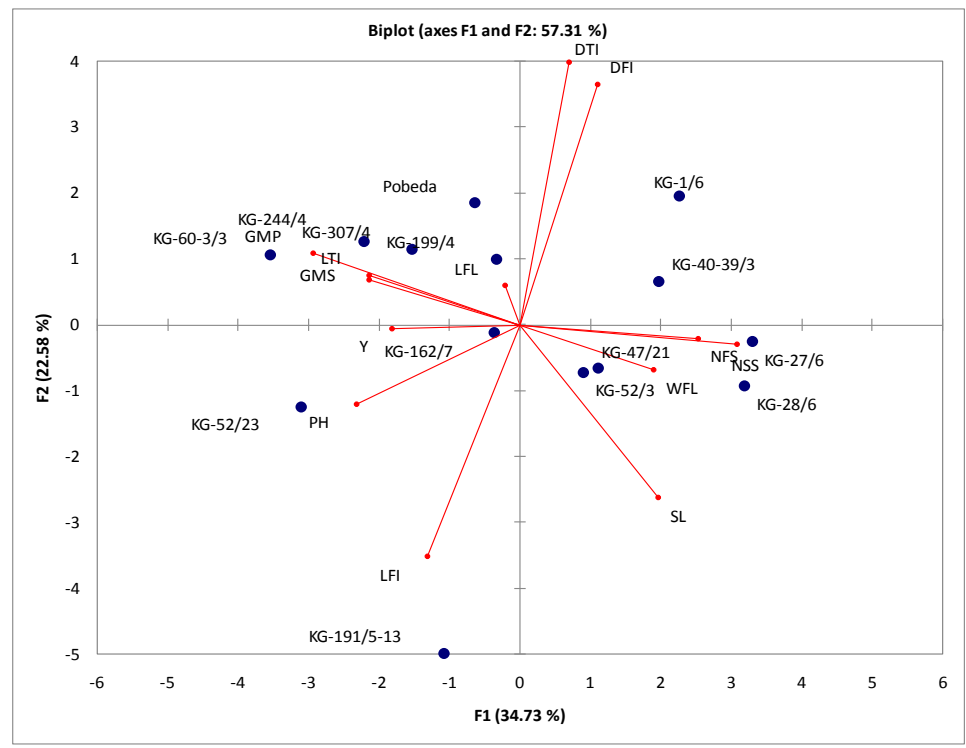

Figure 4. Biplot for the analyzed genotypes and traits shown on the first two main components. Legend:PH-plant height (cm); LFI- length of the first internode (cm); LTI- length of the top internode ( $\mathrm{cm})$; DFI-diameter of the first internode $(\mathrm{mm})$; DTI-diameter of the top internode ( $\mathrm{mm}) ; L F L$ - length of the flag leaf $(\mathrm{cm}) ; W F L$ - width of the flag leaf $(\mathrm{cm}) ; S L$ - spike length $(\mathrm{cm})$; NSS- number of spikelets per spike; NFS-number of fertile spikelets; GMS-grain mass per spike $(\mathrm{g})$; GMP- grain mass per plant $(\mathrm{g})$; Y-yield $\left(\mathrm{t} \mathrm{ha} \mathrm{a}^{-1}\right)$ 
The first two axes shown on the biplot explain $57.31 \%$ of the total variation of the data.

\section{Clustergram}

Figure 5 presents a clustergram of studied genotypes and morphological and productive characteristics of wheat at all three localities.

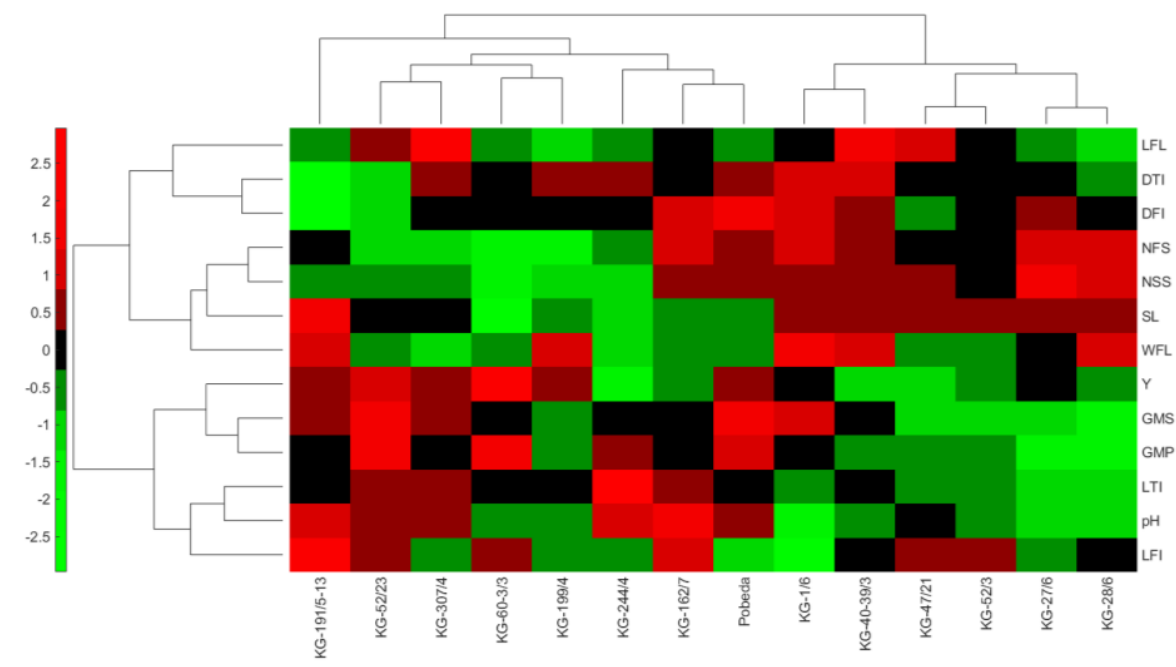

Figure 5. Cluster diagram of analyzed genotypes and morphological and productive traits of wheat. Legend: PH-plant height (cm); LFI- length of the first internode (cm); LTI- length of the top internode (cm); DFI-diameter of the first internode $(\mathrm{mm}) ;$ DTI-diameter of the top internode (mm); LFL- length of the flag leaf $(\mathrm{cm}) ; W F L$ - width of the flag leaf $(\mathrm{cm}) ; S L$ - spike length $(\mathrm{cm})$; NSS- number of spikelets per spike; NFS-number of fertile spikelets; GMS-grain mass per spike $(\mathrm{g})$; GMP- grain mass per plant $(\mathrm{g})$; Y-yield $\left(\mathrm{t} h \mathrm{a}^{-1}\right)$

All morphological and productive traits belong to two clusters. The first clusters consist of two subclusters: the primates DTI, DFI, and LFL and these traits are strongly correlated. They are similarly joined by another subcluster composed of NFS, NSS, SL and WF.

The second cluster consists of two subclusters: the first consisting of three productive traits, Y, GMS, GMP, and the second subcluster composed of three morphological traits (LTI, PH and LFI).

\section{Discussion}

High heritability values of the analysed morphological and productive traits are similar to research of Varsha et al. (2019), Karim and Jahan (2013) and Tripathi et al. (2011). The lowest heritability value was determined for grain yield (48.08\%), which was in agreement with results obtained by Akcura (2009) and Taneva et al. (2019). Opposite to this study, Ali and Shakor (2012) found a high heritability values for bread wheat grain yield $(92.60 \%)$ in arid growing conditions. Out of all the traits that are related to the mechanical strength of the stem (Berry and Berry, 2015), the stem diameter has the highest heritability value (37-56\%), whereas other traits (wall thickness and stem material strength) exhibit heritability between 30 and $40 \%$. 
Based on biplot analysis, the first two axes, PC1 and PC2, were found to account for $57.31 \%$ of the total data variation. A similar proportion of PC1 and PC2 were determined by Sabaghnia and Janmohammadi (2014). Xhulaj et al. (2019) found that the three principal components account for $66.42 \%$ of the total data variation, where the first two components accounting for the largest part of the total variance (PC1 with $28.1 \%$ and PC2 with 24.43\%). The authors emphasize that plant height, spike length, number of spikelet per spike are the most important traits in differentiating genotypes. Janmohammadi et al. (2014) found that five PCA components explained 69\% of the total variation among traits. Authors emphasize that in order to develop high yielding varieties, selection may be made according to the first component defined by to grain number, floret number, tiller number, stem diameter, leaf width and spikelet number.

The NSS, NFS and SL productive traits and the WFL morphological trait are grouped on the positive side of the PCA 1 axis, with a small angle between the vectors, indicating a strong possitive correlation between them. The large angle of the vector of the mentioned properties with respect to the grain yield vector, which is located on the negative side of the PCA 1 axis, indicates a markedly negative correlation. These results were different from the results of previous studies (Zečević et al., 2004; Kumar et al., 2007; Mohammadi et al., 2012; Varsha et al., 2019) in which a positive correlation exists between the components of spike (length spike, number of spikelets per spike, grain weight and the number of grains per spike) and grain yield. However, Hristov et al. (2007, 2011), through Path analysis, identifies a negative direct effect of the number of spikelets per spike on yield per plant, indicating the need to improve their fertility. The spike fertility problem adversely affects the number of grains per spike. The authors note that although the direct effect is not significant, it must be observed since it indicates that the occurrence of sterile spikelets significantly reduces the total yield.

In these studies, the period of stem extension, heading and grain filling was characterised by lower air temperatures and extremely high precipitation at all three localities. Such adverse weather conditions had a detrimental effect on the grain filling process, causing the formation of small, poorly filled grains, which had a negative impact on the yield.

The soil on which the experiments were conducted belongs to different types, with different quality and content of macro and microelements available to the plants. However, due to heavy and unevenly distributed rainfall during the growing season, differences in the quality of the soil on which the trials were conducted did not emerge.

Depending on the temperature and amounts of rainfall at the start of grain filling stage, the coefficients of correlation between the yield and yield components, as well as the quality trait may be positive, negative or close to zero (Rharrabti et al., 2003; Terzić et al., 2018; Rajičić et al., 2019). According to Banjac et al. (2010), unfavourable water regime conditions in 2008/09 led to unexpected values of correlation coefficients, where negative mean strong correlations between plant height and spike mass were found, as well as between plant height and grain mass per spike. These authors point out that for wheat breeding it important correlations that are repeated in different conditions of growing seasons.

The study of the morphological and anatomical features of a stem is very important for a complete and thorough understanding of the processes that cause the lodging of wheat. By lodging, the yield and grain quality are reduced. Cultivars that are resistant to lodging have a wider internodes diameter and a thicker wall (Zuber et al., 1999; PineraChavez et al., 2016). 
The vectors for DTI and DFI are on the positive side of the PCA1 and PCA 2 axes and are very close, indicating a strong positive correlation between these traits as well as a strong negative correlation with the LFI and PH, located on the negative side of the PC2 axis. A strong positive correlation was found between plant height and internode length, stem diameter and leaf length (Sabaghnia and Janmohammadi, 2014), as well as between grain yields, spike length and mass of 1000 grains, whereas negative correlation was found for plant height and stem diameter. Also, a statistically significant positive correlation of grain yield was observed with the length of the spike, the number of spikelets per spike, and the mass of 1000 grains (Varsha et al., 2019). Stem diameter and stem wall thickness, as the major components, are positively correlated with the mechanical strength of the stem (Pinera-Chavez et al., 2016), while the diameter of the stem expressed the strongestrelation with grain yield.

Genotypes KG-1/6, KG-40-39/3, KG-28/6, KG-27/6, KG-47/21 and KG-52/3 are also grouped on the positive side of PCA 1 axis. This indicates that these genotypes reacted similarly in the tested environmental conditions and thus achieved the highest average values of the observed traits. According to the position they occupy on the biplot, the KG-27/6 and KG-28/6 genotypes can be concluded to be very similar to each other and characterized by higher values of NSS, NFS and lower values of GMP, GMS, LTI and PH.

The Y, GMS, GMP (productive) properties of LFL, LTI, PH, and LFI (morphological) are negatively correlated with the first basic component of PCA1 and are on its negative side. Furthermore, the small vector angles for Y, GMS, GMP, PH, and LTI indicate a positive correlation between these features. Also, genotypes KG244/4, KG-199/4, KG-307/4, KG-162/7, KG-52/23, KG-60-3/3, Pobeda and 191/5-13 are grouped on the negative side of the PCA 1 axis, indicating that these genotypes behaved similarly under different environmental conditions.

Looking at the arrangement of wheat genotypes within the cluster, two clusters can be observed. Within each group, there are genotypes of similar productive and morphological characteristics. The first cluster contains the same genotypes as the negative side of the PCA 1 axis and consists of: Pobeda, KG-162/7, KG-244/4, KG199/4, KG-60-3/3, KG-307/4, KG-52/23 and KG-191/5-13. Group II cluster is smaller than group I cluster and contains six wheat genotypes clustered on the positive side of PCA 1 axis (KG-1/6, KG-40-39/3, KG-47/21, KG-52/3 KG -27/6 and KG-28/6).

The cluster diagram indicates that the highest degree of positive correlation is found between the following traits: DTI and DFI; NSS and NFS; GMS and GMP; PH and LTI. In addition to the dendrogram, which shows the similarity of genotypes as well as the similarity of correlation of individual traits, an important element of the cluster is color. It shows the values of individual traits in genotypes. Light red shades indicate higher trait values than average for observed genotypes, and light green shades indicate lower trait values. Black indicates the average. While evaluating the analyzed genotypes of wheat, it is noted that in terms of productive traits, the genotypes KG-191/5-13, KG52/23, KG-307/4 and KG-60-3/3 stood out, while genotypes KG-1/6 and KG-40-39/3 were distinguished in terms of morphological characteristics.

The analysis of wheat genotype pedigree, classified in the same cluster, reveals a similar origin. It is observed that some genotypes in their pedigree have one or both parents in common. Thus, the sister lines KG-28/6 and KG-27/6, which are in the second cluster, have a common origin ( $q$ L-100/97 x $\curvearrowright$ Pobeda) and almost identical morphological and productive features. The Vizija variety is found in the pedigree KG- 
52/3, KG-47/21 and KG-40-39/3, which makes these lines similar to each other in most of the traits analyzed. The Pobeda variety is represented in the pedigree KG-199/4 and KG-307/4, while Studenica is found in the pedigree KG-162/7 and KG-191/5-13. These represent the basis of the similarity of these genotypes and their grouping into the first cluster. It can be observed that some related varieties are in different groups. Thus, Pobeda is in the first cluster, while the genotypes KG-27/6 and KG-28/6, whose germplasm represents the Pobeda variety as one of the parents, are in the second cluster. The difference in stem height between these genetically related genotypes and Pobeda indicates different directions in their selection.

\section{Conclusion}

Analysis of phenotypic expression of morphological and productive traits revealed the adaptability and stability of grain yield of wheat genotypes selected at the Center for Small Grains in Kragujevac (Serbia) in year with extreme wet conditions in the period of intensive wheat development. Appearance of years with prevailing extreme wet conditions is relatively rare but further researches are needed for maintaining satisfactory level of yield and quality of wheat. Genotypes KG-60-3/3 and KG-52/23 achieved the highest average grain yield in all three localities as well as the highest grain mass/plant. The KG-191/5-13 genotype achieved Y, GMS, SL, WFL, PH and LFI above average values in all three localities, while GMP, LTI and NSS were around average. Also, the KG-1/6 genotype had most of the desirable traits above average and can be singled out as a desirable parent in breeding and breeding programs to create new varieties of wheat. In order to increase and enhance biodiversity as well as to create new desirable gene recombinations, it is necessary to hybridize the genotypes of the first and second cluster groups. In progeny resulting from these hybridizations, new lines with improved morphological and productive characteristics can be expected, adapted to different environment as well as stressful environmental conditions.

Acknowledgements. This research was supported by Ministry of Education, Science and Technology Development of Republic of Serbia, Project III 46006. Autors wish to thank the Institute for forage crops in Kruševac (Dr Snežana Babić), as well as Agroinstitute in Sombor (Vladimir Sabadoš) for realization of field experiment.

\section{REFERENCES}

[1] Akcura, M. (2009): Genetic variability and interrelationship among grain yield and some quality traits in Turkish winter durum wheat landraces. - Turkish Journal of Agriculture and Forestry 33: 547-556.

[2] Ali, I. H., Shakor, E. F. (2012): Heritability, variability, genetic correlation and path analysis for quantitative traits in durum and bread wheat under dry farming conditions. Mesopotamia Journal of Agriculture 40(4): 27-39.

[3] Araus, J. L., Slafer, G. A., Royo, C., Serret, M. D. (2008): Breeding for Yield Potential and Stress Adaptation in Cereals. - Critical Reviews in Plant Science 27: 377-412.

[4] Banjac, B., Petrović, S., Dimitrijević, M., Dozet, D. (2010): Estimation of correlation coefficient among yield parameters of wheat under stress conditions. - Annals of Agronomy 34(1): 60-68.

[5] Berry, P. M., Sylvester-Bradley, R., Berry, S. (2007): Ideotype design for lodgingresistant wheat. - Euphytica 154: 165-179. 
[6] Berry, P. M., Berry, S. T. (2015): Understanding the genetic control of lodging-associated plant characters in winter wheat (Triticum aestivum L.). - Euphytica 205(3): 671-689.

[7] Bhutta, W. M., Ibrahim, M., Tahira, A. (2006): Association analysis of some morphological traits of wheat (Triticum aestivum L.) under field stress conditions. Plant, Soil and Environment 52(4): 171-177.

[8] Hristov, N., Mladenov, N., Kondić-Špika, A. (2007): Environmental stability of physical traits of wheat grain. - Proceedings of the Institute of Field and Vegetable Crops, Novi Sad 43: 29-37.

[9] Hristov, N., Mladenov, N., Kondić-Špika, A., Marjanović-Jeromela, B., Jocković, B., Jaćimović, B. (2011): Effect of environmental and genetic factors on the correlation and stability of grain yield components in wheat. - Genetika 43(1): 141-152.

[10] Janmohammadi, M., Movahedi, Y., Sabaghnia, N. (2014): Multivariate statistical analysis of some traits of bread wheat for breeding under rainfed conditions. -Journal of Agricultural Sciences 59(1): 1-14.

[11] Karim Hasnat, M. D., Jahan, M. A. (2013): Study of Lodging Resistance and Its Associated Traits in Bread Wheat. - Journal of Agricultural and Biological Science 8(10): 683-687.

[12] Kumar, N., Kulwal, P. L., Balyan, H. S., Gupta, P. K. (2007): QTL mapping for yield and yield contributing traits in two mapping populations of bread wheat. - Molecular Breeding 19: 163-177.

[13] Mladenov, N., Denčić, S., Hristov, N. (2007): Breeding for grain yeld and components of yeld in wheat. - Proceedings of the Institute of Field and Vegetable Crops 43: 21-27.

[14] Mohammadi, M., Karimizadeh, R., Sabaghnia, N., Shefazadeh, M. K. (2012): Genotype environment interaction and yield stability analysis of new improved bread wheat genotypes. - Turkish Journal of Field Crops 17(1): 67-73.

[15] Pinera-Chavez, F. J., Berry, P. M., Foulkes, M. J., Molero, G., Reynolds, M. P. (2016): Avoiding lodging in irrigated spring wheat. II. Genetic variation of stem and root structural properties. - Field Crops Research 196: 64-74.

[16] Rajičić, V., Perišić, V., Madić, M., Popović, V., Perišić, V., Luković, K., Terzić, D. (2019): Grain yield and quality of winter wheat cultivars. - Proceeding of the $X$ International Scientific Agricultural Symposium “Agrosym 2019”, Jahorina.

[17] Rharrabti, Y., Garcíadel Moral, L. F., Villegasb, D., Royo, C. (2003): Durum wheat quality in Mediterranean environments III. Stability and comparative methods in analysing $\mathrm{G} \times$ E interaction. - Field Crop Research 80: 141-146.

[18] Sabaghnia, N., Janmohammadi, M. (2014): Interrelationships among some morphological traits of wheat (Triticum aestivum L.) cultivars using biplot. - Botanica Lithuanica 20(1): $19-26$.

[19] Stanojević, G. (2012): Analysis of annual precipitation sums in Serbia. - Journal of the Geographical Institute "Jovan Cvijić" 62(2): 1-13.

[20] Taneva, K., Bozhanova, V., Petrova, I. (2019): Variability, heritability and genetic advance of some grain quality traits and grain yield in durum wheat genotypes. Bulgarian Journal of Agricultural Science 25(2): 288-295.

[21] Terzić, D., Đekić, V., Milivojević, M., Branković, S., Perišić, V., Perišić, V., Đokić, D. (2018): Yield components and yield of winter wheat in different years of research. Biological Nyssana 9(2): 119-131.

[22] Tošić, I., Unkašević, M. (2013): Climate changes in Serbia. - Monography, Belgrade.

[23] Tripathi, S. N., Marker, S., Pandey, P., Jaiswal, K. K., Tiwari, D. K. (2011): Relationship between Some Morphological and Physiological Traits with Grain Yield in Bread Wheat (Triticum aestivum L. em.Thell.). - Trends in Applied Sciences Research 6(9): 10371045.

[24] Varsha, J., Verma, P., Saini, P., Singh, V., Yashvee, S. (2019): Genetic variability of wheat (Triticum aestivum L.) genotypes for agro-morphological traits and their 
correlation and path analysis. - Journal of Pharmacognosy and Phytochemistry 8(4): 2290-2294.

[25] Xhulaj, D. B., Elezi, F., Hobdari, V. (2019): Interrelation ships among traits and morphological diversity of wheat (Triticum aestivum L.) accessions in base collection of Plant Genetic Resources Institute, Albania. - Acta Agriculturae Slovenica 113(1): 163179.

[26] Xu, X., Gao, P., Zhu, X., Guo, W., Ding, J., Li, C. (2018): Estimating the responses of winter wheat yields to moisture variations in the past 35 years in Jiangsu Province of China. - PLoS One 13(1): 191-217.

[27] Yao, J., Ma, H., Zhang, P., Ren, L., Yang, X., Yao, G., Zhang, P., Zhou, M. (2011): Inheritance of stem strength and its correlations with culm morphological traits in wheat (Triticum aestivum L.). - Canadian Journal of Plant Science 91: 1065-1070.

[28] Yu, Z., Li, Z., Yan, B. (2003): Multiple correlation analysis on physical strength and properties of wheat stalk. - Hubei Agricultural Sciences 1(4): 11-14.

[29] Zampieri, M., Ceglar, A., Dentener, F., Toreti, A. (2017): Wheat yield loss attributable to heat waves, drought and water excess at the global, national and subnational scales. Environmental Research Letters 12(6): 1-11.

[30] Zečević, V., Knežević, D., Mićanović, D. (2004): Genetic correlations and pathcoefficient analysis of yield and quality components in wheat (Triticum aestivum L.). Genetica 36(1): 13-21.

[31] Zuber, U., Winzeler, H., Messmer, M. M., Keller, M., Keller, B., Schmid, J. E., Stamp, P. (1999): Morphological traits associated with lodging resistance of spring wheat (Triticum aestivum L.). - Journal of Agronomy and Crop Science 182: 17-24. 